\title{
Combined use of optical and radar satellite data for the monitoring of irrigation and soil moisture of wheat crops
}

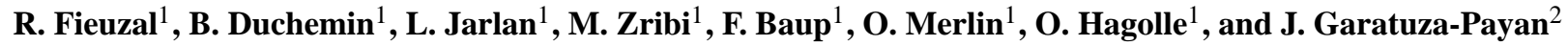 \\ ${ }^{1}$ CESBIO, Centre d'études spatiales de la biosphère, UMR 5126, CNES-CNRS-IRD-UPS, Toulouse, France \\ ${ }^{2}$ ITSON, Instituto Tecnológico de Sonora, Departamento de Ciencias del Agua y del Medio Ambiente, 5 de Febrero 818 Sur, \\ Cd. Obregón, Sonora, 85000, Mexico
}

Received: 22 July 2010 - Published in Hydrol. Earth Syst. Sci. Discuss.: 25 August 2010

Revised: 11 March 2011 - Accepted: 17 March 2011 - Published: 5 April 2011

\begin{abstract}
The objective of this study is to get a better understanding of radar signal over irrigated wheat fields and to assess the potentialities of radar observations for the monitoring of soil moisture. Emphasis is put on the use of high spatial and temporal resolution satellite data (Envisat/ASAR and Formosat-2). Time series of images were collected over the Yaqui irrigated area (Mexico) throughout one agricultural season from December 2007 to May 2008, together with measurements of soil and vegetation characteristics and agricultural practices. The comprehensive analysis of these data indicates that the sensitivity of the radar signal to vegetation is masked by the variability of soil conditions. On-going irrigated areas can be detected all over the wheat growing season. The empirical algorithm developed for the retrieval of topsoil moisture from Envisat/ASAR images takes advantage of the Formosat-2 instrument capabilities to monitor the seasonality of wheat canopies. This monitoring is performed using dense time series of images acquired by Formosat- 2 to set up the SAFY vegetation model. Topsoil moisture estimates are not reliable at the timing of plant emergence and during plant senescence. Estimates are accurate from tillering to grain filling stages with an absolute error about $9 \%$ $\left(0.09 \mathrm{~m}^{3} \mathrm{~m}^{-3}, 35 \%\right.$ in relative value $)$. This result is attractive since topsoil moisture is estimated at a high spatial resolution (i.e. over subfields of about 5 ha) for a large range of biomass water content (from 5 and $65 \mathrm{tha}^{-1}$ ) independently from the viewing angle of ASAR acquisition (incidence angles IS1 to IS6).
\end{abstract}

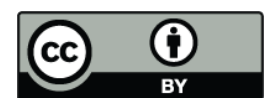

Correspondence to: R. Fieuzal (remy.fieuzal@cesbio.cnes.fr)

\section{Introduction}

Effective management and monitoring of environmental resources require integrating hydro-ecologic parameters into biophysical models. However, although models performances have continuously been improved over the past years, regional applications for the management of agricultural water are still limited because of the shortage of key input modelling data over large areas (Boote et al., 1996; Moulin et al., 1998; Faivre et al., 2004). The monitoring of farming practices and soil-vegetation biophysical variables combining modeling and remote sensing data offers both advantages. On one hand, punctual parameters derived from satellite acquisition can be used as input to constrain models. On other hand, the continuous and spatialized modeled variables can be used to improve the knowledge on the information derived from remote sensing data.

Recently designed earth observing systems offer both high spatial resolution and frequent revisit time. This is particularly promising for the seasonal monitoring of croplands at a field scale. At the present time, the Formosat-2 satellite provides $8 \mathrm{~m}$ resolution images (in the multispectral mode at nadir viewing) for 4 narrow spectral bands ranging from $0.45 \mu \mathrm{m}$ to $0.90 \mu \mathrm{m}$ (blue, green, red and near-infrared). It is a unique tool to monitor the seasonality of biophysical variables such as leaf area index (Duchemin et al., 2008a; Bsaibes et al., 2009; Hadria et al., 2009a). In the microwave spectral domain, the ASAR radar onboard the Envisat mission is an active instrument operating at C-band with a 30 $\mathrm{m}$ spatial resolution in the Alternating Polarisation mode. The orbit cycle is 35 days, but the combination of acquisitions at different incidence angles allows revisiting of a few days (Torres et al., 1999). The continuity of combined high

Published by Copernicus Publications on behalf of the European Geosciences Union. 
resolution and repetitivity data sets in the microwave and the optical spectral domains is insured in the near future by the planned launch of Sentinel-1 and Sentinel-2 satellite missions (ESA, 2007, cited in Hagolle et al., 2008).

Optical satellite data were intensively used in the context of crop monitoring to provide space and time regular observations of plant biophysical variables (Asrar et al., 1984; Baret and Guyot, 1991; Carlson and Ripley, 1997; Bastiaanssen et al., 2000; Duchemin et al., 2006). In contrast, there is still a poor understanding of the radar response over annual crops (Moran et al., 2002). For wheat canopies, the sensitivity of the radar backscattering co-polarization ratio is caused by the differential attenuation of horizontally and vertically polarized electromagnetic waves that propagate through a medium with vertical structure (Bracaglia et al., 1995; Picard et al., 2003). Some attempts at using empirical relationships between Envisat/ASAR backscattering coefficient and wheat leaf area index characteristics have been performed (Dente et al., 2008). The limitation of these methods lies in the saturation of the signal with the density of canopies and its sensitivity to surface roughness and topsoil moisture (Moran et al., 2002; Mattia et al., 2003; Ulaby et al., 1986; Beaudoin et al., 1990; Satalino et al., 2003; Zribi et al., 2003). The general trends of the radar response as a function of soil conditions and the sensor characteristics (frequency, incidence, polarisation) are well captured by backscatter models (e.g. Jarlan et al., 2002), but the operational applicability of inversion schemes is still challenging since the parameters required for modelling are difficult to estimate over large areas and since the relative contribution of these parameters on the signal is difficult to decouple.

In this context, the objective of this study is twofold: (i) to get a better understanding of radar signal over irrigated wheat fields and, (ii) to show the potentialities of radar observations for the monitoring of irrigation and soil moisture. The study is carried out over an irrigated area located in NorthWest of Mexico (arid climate with $200 \mathrm{~mm}$ of rain per year). Emphasis is put on time series of high spatial resolution images $(30 \mathrm{~m})$ provided by Envisat/ASAR. The potentialities of these data for the monitoring of soil conditions is analysed based on spatial estimates of Biomass Water Content (BWC). These estimates are obtained over a large number of fields using a simple wheat growth model controlled by Formosat-2 data. The analysis of the covariations of backscattering coefficients and BWC shows the high sensitivity of the radar response to the irrigation status. It allowed developing an original method for the retrieval of topsoil moisture based on the spatial variation of backscattering coefficients under a large range of vegetation growing stage.
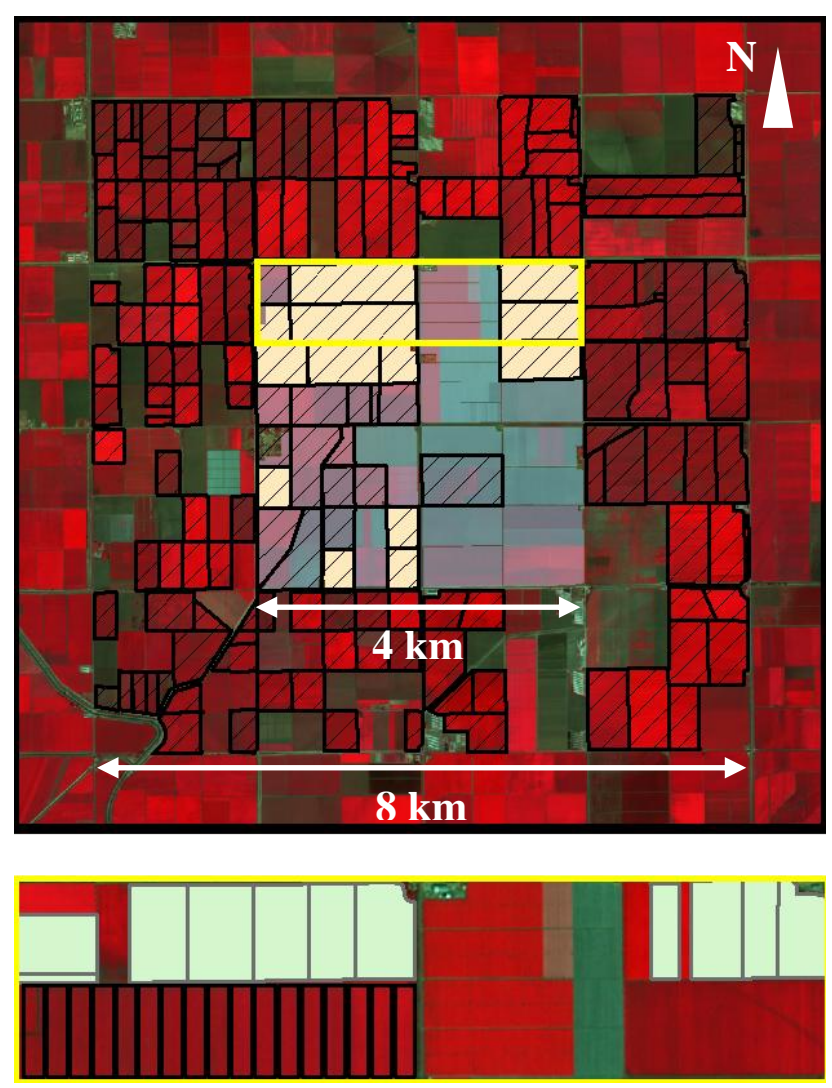

Fig. 1. The $8 \times 8 \mathrm{~km}^{2}$ study area delineated on a Formosat- 2 image, with its $4 \times 4 \mathrm{~km}^{2}$ central part highlighted. Wheat fields are hatched in black. Agricultural practices were collected on 12 wheat fields (beige fields). The bottom zoomed yellow area shows the largest fields where grain yield (green subfields) and irrigation (black segments) were collected.

\section{Overview of the experiment}

\subsection{Study area}

The experiment was conducted throughout one agricultural season from November 2007 to June 2008 in the Yaqui Valley, North-West of Mexico $\left(27.25^{\circ} \mathrm{N}, 109.88^{\circ} \mathrm{W}\right)$. The objective of the experiment was to characterize the spatial variability of surface fluxes from the field to regional (few $\mathrm{km}$ ) scale. Field measurements were collected on an $8 \times 8 \mathrm{~km}^{2}$ irrigated cropping area where land use was exhaustively collected (Fig. 1). Wheat was the dominant crop covering $60 \%$ of the study area.

The study area is adequate to get a better understanding of the radar signal over wheat fields since: (i) it is flat, thus radar backscattering is not influenced by topography, (ii) fields are large (up to 100 ha), with only two different North-South and East-West row orientations, (iii) agricultural practices are almost identical for all the wheat fields: mechanized tillage, irrigation and fertilization operations applied in the course of programmed schedules. 


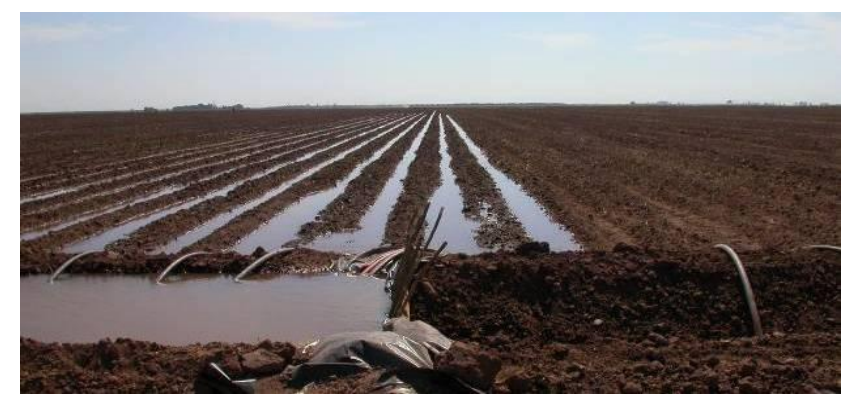

Fig. 2. Picture taken on the largest field at the irrigation limit (before sowing).

\subsection{Experimental data}

Wheat fields located in the $4 \times 4 \mathrm{~km}^{2}$ central part of the $8 \times 8 \mathrm{~km}^{2}$ area were intensively monitored during the experiment. Climatic data, agricultural practices, vegetation and soil biophysical variables were collected regularly during all the agricultural season.

Climatic data were collected by a meteorological station installed at the center of the study area between 27 December 2007 and 17 May 2008. Air temperature and solar radiation were collected at a semi-hourly time step, from which daily mean air temperature average and daily accumulated global incoming radiation were computed.

Agricultural practices were collected on 12 wheat fields located within the $4 \times 4 \mathrm{~km}^{2}$ centre (see Fig. 1). Sowing and irrigation dates are used in this study. Sowing period was from 25 November 2007 and 8 January 2008, with a preirrigation performed to prepare the seedling. After sowing, wheat crops were irrigated 3 to 4 times. Furrow irrigation was used (Fig. 2), with a water quantity of $150 \mathrm{~mm}$ each time. Harvesting was performed from April end to May.

Vegetation measurements consist in Green Leaf Area index (GLA) and Grain Yield (GY) estimates. GLA data were derived from hemispherical photography taken on $20 \times 20 \mathrm{~m}^{2}$ plot following the VALERI protocol (Garrigues et al., 2006) based on the analysis of canopy directional gap fraction. At the end of the season, grain yield was estimated on 11 fields by surveying harvesting machine with GPS system on track mode (see the zoomed part in Fig. 1).

Topsoil moisture was measured using TDR sensors installed within 2 pits, at $5 \mathrm{~cm}$ depth. During the agricultural season, data were collected on 2 wheat fields at a semihourly time step. These measurements were calibrated and transformed in volumetric soil moisture by comparison with gravimetric measurements. The values the closest to ASAR acquisition dates are used in this study; the time gap between satellite acquisitions and in situ measurements never exceeds $15 \mathrm{~min}$.

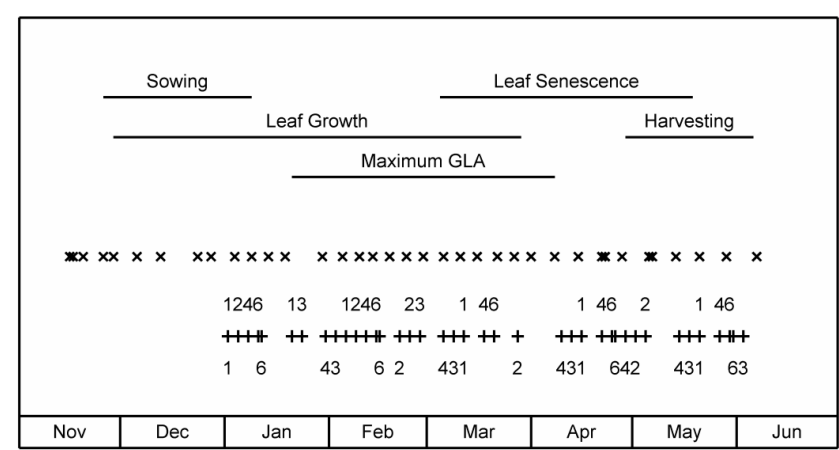

Fig. 3. Satellite acquisition dates ( $\times$ Formosat $-2,+$ Envisat/ASAR) together with the main phenological stages of wheat crops. The ASAR acquisition mode is indicated (top number: ascending overpass; bottom number: descending overpass; the number indicates the illumination/viewing angle from IS1 to IS6).

\subsection{Remote sensing data}

Two series of satellite acquisitions were specifically programmed during the experiment. The acquisition dates are shown in Fig. 3, together with the phenological main phases and agricultural operations for wheat crops. 37 optical images were acquired by the Formosat-2/RSI sensor, from 15 November 2007 to 6 June 2008. 43 radar images were acquired by the Envisat/ASAR sensor, from 1 January 2008 to 2 June 2008. The main characteristics of these images and their preprocessing are detailed below.

\subsubsection{Formosat-2 data}

The Formosat-2 Taiwanese satellite was launched in May 2004. The remote sensing instrument onboard Formosat-2 provides high spatial resolution images $(8 \mathrm{~m}$ in the multispectral mode at nadir viewing) in four narrow spectral bands ranging from $0.45 \mu \mathrm{m}$ to $0.90 \mu \mathrm{m}$ (blue, green, red and near-infrared). Unlike other systems operating at high spatial resolution, Formosat-2 may observe a particular area every day with the same viewing angle. However, only a part - about the half - of the Earth may be observed. More details about the specific orbital cycle and other characteristics of the Formosat-2 mission could be found in Chern et al. (2008) as well as on the internet (http://www.nspo.org.tw, http://www.spot-image.com).

The images were acquired at around 10:30 GMT with a nominal time step of 5 days and a constant view zenith angle of about $12^{\circ}$. The area was practically could free during the experiment and the maximal lag between two acquisitions was 10 days. The images were geometrically corrected by applying cross-correlation to a reference image which was geo-registered in the UTM-12N projection system based on a set of GPS ground control points. Accuracy in geolocalisation was estimated to about half-pixel $(4 \mathrm{~m})$. Atmospheric correction was performed using the SMAC code (Rahman 
and Dedieu, 1994) with an original method developed by Hagolle et al. (2008) for the retrieval of aerosol optical thickness. Finally, top-of-canopy NDVI is computed as the ratio of the difference between near infrared and red reflectances to their sum.

\subsubsection{Envisat-ASAR data}

The Advanced Synthetic Aperture Radar (ASAR), onboard the Envisat mission (http://envisat.esa.int/) launched in March 2002, operates at C-band (frequency $5.33 \mathrm{GHz}$, wavelength $5.6 \mathrm{~cm}$ ) with 7 different incidence angles between $15^{\circ}$ and $45^{\circ}$. The orbital cycle of Envisat/ASAR is 35 days, but the combination of different illumination/viewing configurations allows to increase the repetitivity of observations (e.g. 10 passes during the 35 -day orbital cycle at $45^{\circ}$ latitude).

The images were acquired for all possible ascending and descending overpasses and incidence angles in the Alternating Polarisation mode at $30 \mathrm{~m}$ spatial resolution. The data set includes images acquired at five different swaths IS1, IS2, IS3, IS4 and IS6, characterized by their incidence angle of about $19^{\circ}, 23^{\circ}, 28.7^{\circ}, 33.7^{\circ}$ and $41^{\circ}$ respectively. Radiometric calibration was performed following the procedure specified by the European Space Agency. Geometric reprojection was performed using the BEST software tools available at the ESA web site (http://earth.esa.int/best/). Visual crossexamination of ASAR and Formosat-2 images shows that the accuracy of ASAR image geolocation was about $50 \mathrm{~m}$, which is much lower than the size of fields. The backscattering coefficients in $\mathrm{HH}$ polarization $\left(\sigma^{0} \mathrm{HH}\right)$ and VV polarization $\left(\sigma^{0} \mathrm{Vv}\right)$ were averaged over large geographical units. These geographic units are automatically generated in the wheat fields, taking advantage of their rectangular shape. In detail, each field may be subdivided into one or several smaller entities covering at least 320 pixels (about 5 hectares) using the following rules: (i) all small areas are located within a single field to avoid disturbance that may be caused by irrigation ditches, roads and buildings, (ii) each small area is about $500 \mathrm{~m}$ along the direction of irrigation channels and $100 \mathrm{~m}$ across the direction of irrigation channels. Since $100 \mathrm{~m}$ corresponds to the distance that can be irrigated during one day, this second rule ensures to have a maximum homogeneity in the moisture status of each small area.

In order to evaluate Envisat performances over the considered spatial units, confidence intervals for each viewing angles were estimated accounting for: (i) the radiometric resolution, (ii) the radiometric accuracy and (iii) the radiometric stability. The radiometric resolution was derived from Eqs. (1) and (2). The values of the radiometric stability $(0.50 \mathrm{~dB})$ and the radiometric accuracy $(0.57 \mathrm{~dB})$ are listed in Torres et al. (1999). Assuming all errors are independent and can be summed, we estimated that the confidence interval at 1 standard deviation of ASAR measurements over 5 ha areas ranges from $\pm 0.86 \mathrm{~dB}$ for images acquired at IS1 to $\pm 0.82 \mathrm{~dB}$ for images acquired at IS6.

$R_{\mathrm{rad}}=10 \times \log \left(1 \pm 1 / \sqrt{\mathrm{NL}_{\mathrm{eff}}}\right)$ with

$\mathrm{NL}_{\text {eff }}=N_{\text {p_az }} \times N_{\text {p_ra }} \times \mathrm{NL}_{\text {az }} \times \mathrm{NL}_{\text {ra }} / R$

Where :

$\mathrm{NL}_{\text {eff }}, \mathrm{N}_{\mathrm{p}_{-} \mathrm{az}}, \mathrm{N}_{\mathrm{p} \_\mathrm{ra}}, \mathrm{NL}_{\mathrm{az}}$, and $\mathrm{NL}_{\mathrm{ra}}$ denote the effective look number, the number of azimuthal pixels (8), the number of range pixels (40), the number of azimuthal looks (Eq. 2) and the number of range looks (1 to 1.8), respectively.

$R$ is the number of pixels per independent pixel in the data product and can be calculated as follows:

$R=\left(\rho_{\mathrm{az}} / \Delta_{\text {spa_az }}\right) \times\left(\rho_{\text {ground_ra }} / \Delta_{\text {spa_ra }}\right)$

Where :

$\rho_{\text {az }}, \rho_{\text {groud_ra }}, \Delta_{\text {spa_az }}, \Delta_{\text {spa_ra }}$, denote the azimuthal spatial resolution $(30 \mathrm{~m})$, the ground range spatial resolution $(30 \mathrm{~m})$ and the azimuth and ground range pixel spacing $(12.5 \mathrm{~m})$.

\section{Biomass water content}

\subsection{Overview of the SAFY model}

The Simple Algorithm For Yield estimates (SAFY) is a daily time step vegetation model. It simulates the time courses of Green Leaf Area index (GLA), and Dry Above-ground Mass (DAM) from incoming global radiation and mean air temperature. These two variables are simulated from the plant emergence to total senescence. The DAM production depends on the photosynthetically active portion of solar radiation absorbed by plants, balanced by the light-use-efficiency (Monteith and Moss, 1977). The main phenological stages are controlled by a degree-day approach: during the leaf growing period, a fraction of the daily DAM production is dedicated to the daily leaf production following the empirical parametrization proposed by Maas (1993); the senescence occurs at a prescribed rate when the air temperature accumulated from emergence reaches the senescence temperature. The biomass water content is estimated from the dry aerial mass assuming that the plant water content is $85 \%$ from emergence to the day when the senescence starts, then decreasing linearly to reach $20 \%$ at the end of the senescence phase. A detailed description of the SAFY model can be found in Duchemin et al. (2008b).

\subsection{Model set up and evaluation}

The methodological key-points and the main results are summarized here. A detailed presentation is described in Duchemin et al. (2010).

The key variable to control the SAFY model is GLA, which was mapped from each Formosat-2 data using an empirical relationship between in-situ GLA data derived 


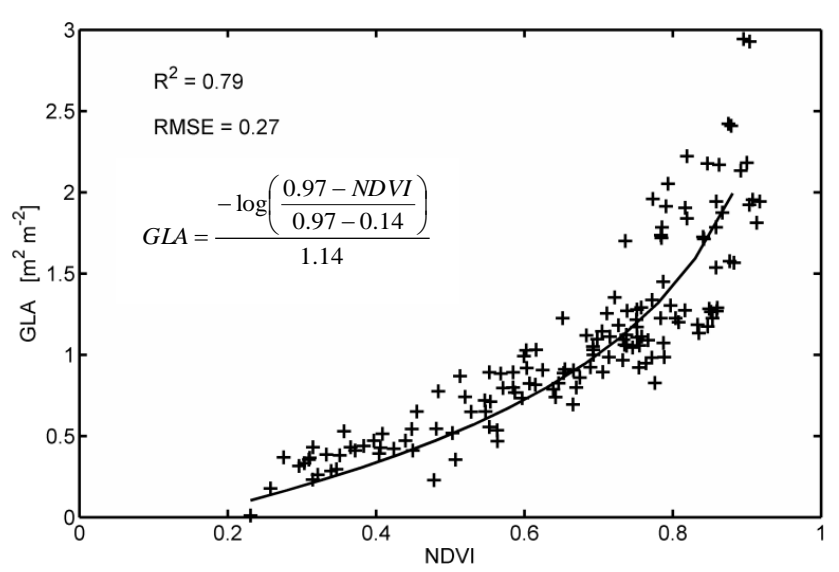

Fig. 4. Relationship between Normalized Difference Vegetation Index (NDVI, derived from Formosat-2 images) and Green Leaf Area (GLA, derived from field measurements). The determination coefficient and the root mean square error associated to the retrieval of GLA using a logarithmic relationship (full line) are displayed with label " $R$ " " and "RMSE", respectively.

from hemispherical photography and NDVI derived from Formosat-2 images. The NDVI shows a logarithmic response to GLA (Fig. 4), in agreement with the results obtained in previous studies (Asrar et al., 1984; Baret and Guyot, 1991; Duchemin et al., 2006). There is a close correlation between the two variables, with a determination coefficient $R^{2}$ of 0.79 and an RMSE of $0.27 \mathrm{~m}^{2} \mathrm{~m}^{-2}$ (25\% in relative value, computed as RMSE divided by the mean of observed values).

The model was calibrated following the method discussed in Duchemin et al. (2008b). Time series of GLA derived from Formosat-2 images were built by simple averaging on each elementary spatial unit (i.e. subfield of about $5 \mathrm{ha}$ ) of interest. Four parameters were optimized: the day of emergence, the effective light-use efficiency, the thermal threshold corresponding to the beginning of the senescence of leaves, and one parameter of the leaf partitioning function. The optimisation step was based on minimization of the root mean square error between simulated GLA (SAFY model) and observed GLA (derived from NDVI time series).

The simulations were evaluated using three different criteria. Firstly, for the 528 wheat sub-fields of the study area, the relative difference between GLA simulated by SAFY and derived from Formosat-2 was on average 12\% and 26.5\% at maximum. This limited range of error appears satisfactory with regards to the accuracy of in-situ GLA measurements (Weiss et al., 2004). Secondly, for the fields where the agricultural practices were collected, we checked the consistency between emergence dates retrieved by optimisation and sowing dates collected at field: a high agreement was found ( $R^{2} \sim 0.86$, slope of 1.02) and the lag between sowing and emergence (on average 10 days) was coherent. Thirdly, for the 11 fields where harvesting was monitored, we found that the dry aerial mass simulated at the end of the season varies between 9.5 and $13.5 \mathrm{tha}^{-1}$, while the grain yield observed at field ranges between 4 and $8 \mathrm{tha}^{-1}$. The two variables were found well correlated $\left(R^{2} \sim 0.91\right)$. The difference between grain yield and total crop production $\left(5 \mathrm{tha}^{-1}\right)$ appears consistent with values of harvest index for wheat crops. These values appear also in agreement with what have been observed by Rodriguez et al. (2004); Lobell et al. (2005); OrtizMonasterio and Lobell (2007) over the same region. These performances appear comparable to those of previous modelling experiment based on the SAFY model on wheat crops in Morocco as well as on maize and sunflower on southwest of France (Duchemin et al., 2008b; Hadria et al., 2009; Claverie et al. 2009).

\section{Sensitivity of radar backscatter to irrigation and topsoil drying}

In order to bring to light the sensitivity of radar data to the soil water status, we selected the largest field $\left(0.5 \times 1.9 \mathrm{~km}^{2}\right)$ located in the North of the central area (see the Fig. 1 zoomed area and the picture in Fig. 2). This field experienced three irrigations during the season, each time the duration being about 17 days. It was thus separated in 17 segments covering about $5.5 \mathrm{ha}$; each irrigated in one day. On each segment, the mean backscattering coefficient $\left(\sigma^{0} \mathrm{HH}\right)$ derived from Envisat/ASAR images and the mean Biomass Water Content (BWC) simulated by SAFY were extracted. Then we analyzed discontinuities and trends in $\sigma^{0}{ }_{\mathrm{HH}}$ from one segment to the next and/or from one side of the field to the other. The analysis was carried out during and out of irrigation periods.

Figure 5 shows the result of this analysis at two different dates with same orbit (ascending) and incidence angle (IS4): $11 / 02 / 2008$, during the first irrigation time in case of a moderate biomass water content (BWC between 5 and $15 \mathrm{tha}^{-1}$ ), and 17/03/2009, during the second irrigation time in case of a high biomass water content (BWC between 20 and $45 \mathrm{tha}^{-1}$ ). The spatial variation of the backscattering coefficient appeared in agreement with both the vegetation development stage and the irrigation status: for the first date, $\sigma^{0} \mathrm{HH}$ is about $-7.5 \mathrm{~dB}$ over recently irrigated segments (numbers 4 and 5 in Fig. 5a), while it is around $-11 \mathrm{~dB}$ over the driest part (segments 7 to 17 in Fig. 5a); for the second date, $\sigma^{0} \mathrm{HH}$ is about $-9 \mathrm{~dB}$ over recently irrigated segments (numbers 13 to 15 in Fig. 5b), while it is around $-12 \mathrm{~dB}$ over the driest area (segments 16 and 17 in Fig. 5b). Despite the attenuation of the radar backscattering due to increasing biomass water content in the canopy, the irrigation limit is still clearly visible in both cases. Furthermore, we can clearly observe the decrease in $\sigma^{0} \mathrm{HH}$ from the segments recently irrigated to the segments previously irrigated (from segments 1 to 4 in Fig. 5a, and from segments 1 to 15 in Fig. 5b). 


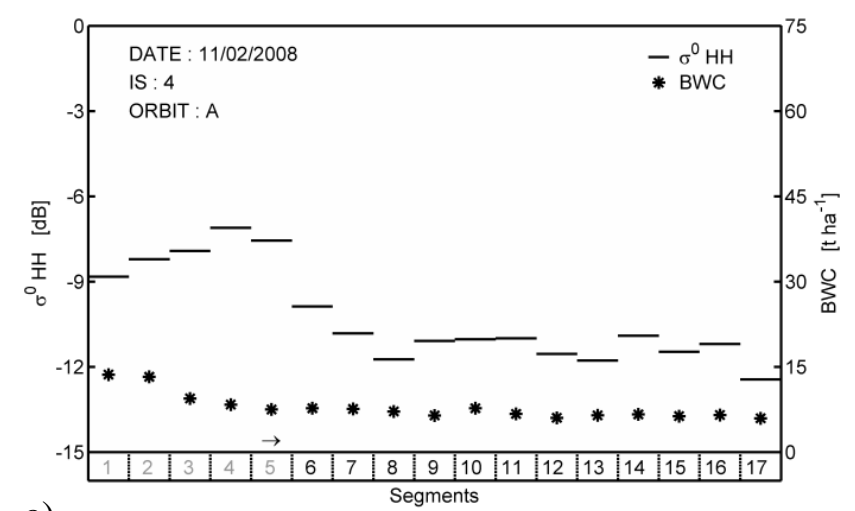

a)

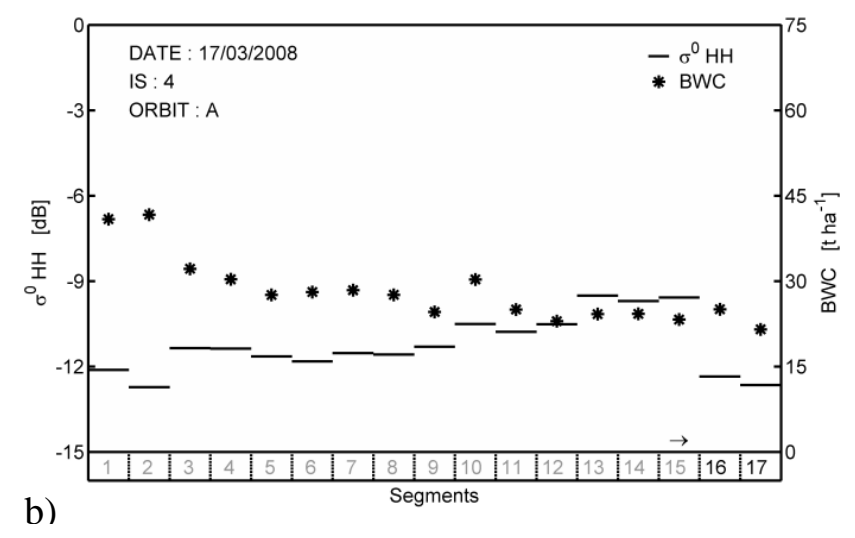

Fig. 5. Spatial variations of backscattering coefficient and biomass water content over the different segments of the largest wheat field on two dates: (a) 11/02/08, first irrigation time, (b) 17/03/08, second irrigation time. The irrigation status is indicated (grey: irrigated, black: non irrigated), the arrow indicates the direction of the irrigation-watercourse.

Figure 6 displays the same as Fig. 5 for the three images successively acquired after the first irrigation time on the $24 / 02 / 2008$, the $27 / 02 / 2008$ and the $05 / 03 / 2008$. As the entire field has been irrigated at these times, no discontinuity is observed between the segments, but a rather smooth increase of backscattering coefficients from one side of the field (segment 1 in Fig. 6) to the other (segment 17 in Fig. 6): the segments that have been irrigated the earliest (latest) show the lowest (highest) value of $\sigma^{0} \mathrm{HH}$. The slope of the decrease is on average $0.4,0.3$ and $0.1 \mathrm{~dB}$ from one segment to the next for the images acquired 1, 4 and 11 days after irrigation ends, respectively. The difference between the two opposite sides of the field (between segments numbered 1 and 17 in Fig. 6) is about $7 \mathrm{~dB}$ just after the irrigation date and only $2 \mathrm{~dB} 11$ days after the same event. This reduction appears consistent with the dynamics of topsoil moisture, soil drying resulting in lower and more homogeneous topsoil moisture with time.
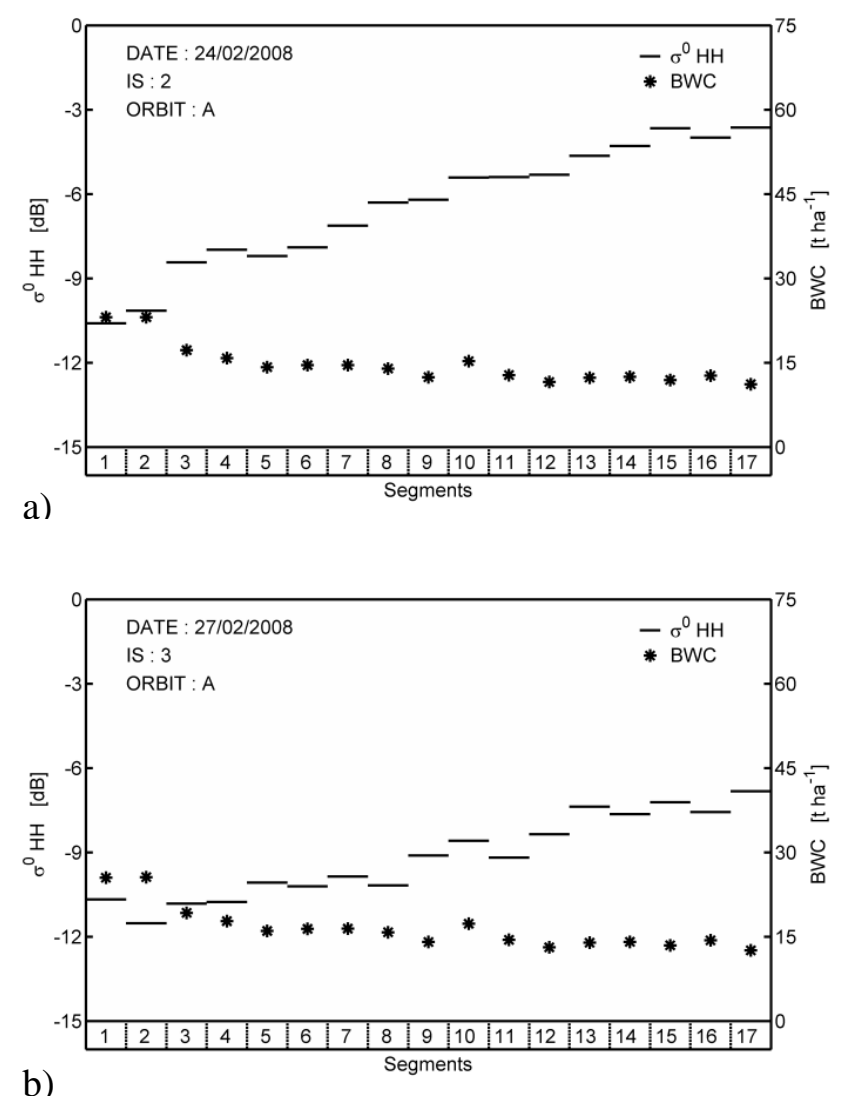

b)

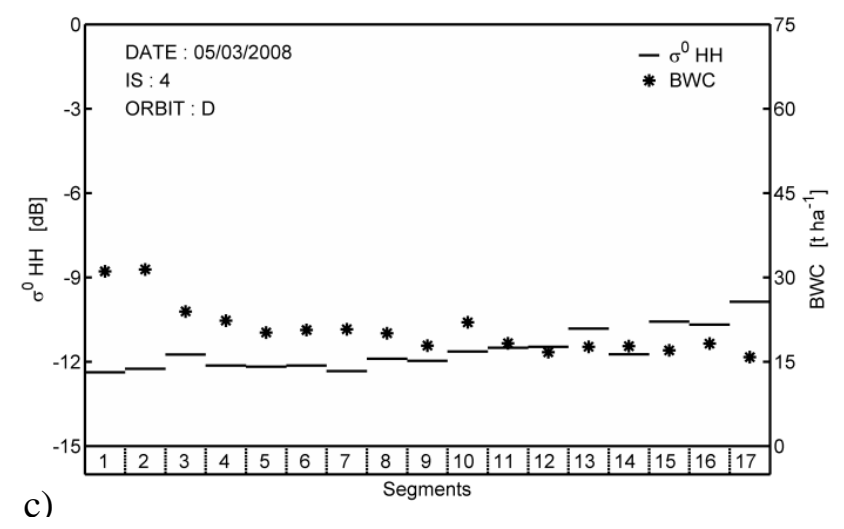

Fig. 6. Spatial behaviour of backscattering coefficient and biomass water content for three images acquired after the first irrigation time: (a) 24/02/2008, (b) 27/02/2008, (c) 05/03/2008.

In order to extend this analysis to all the data set, we used two quantitative indices that describe $\sigma^{0} \mathrm{HH}$ variations along the various segments of the largest field: amplitude and trend. The amplitude $(\Delta \sigma)$ is the difference between the maximum and the minimum value of $\sigma^{0} \mathrm{HH}$ for all the possible combination of three successive segments. $\Delta \sigma$ is supposed to be maximal for the area centered on the segment under irrigation. The Trend (T $\sigma)$ is calculated as the slope of the $\sigma^{0} \mathrm{HH}$ per segment number for the images acquired out of irrigation 
Table 1. Characteristics of Envisat/ASAR images and $\sigma^{0} \mathrm{HH}$ statistics (minimal, mean, maximal values, amplitude $\Delta \sigma$ and the trend T $\sigma$ ) derived from the 17 segments of the largest wheat field, together with the average value of biomass water content BWC during the irrigation period.

\begin{tabular}{|c|c|c|c|c|c|c|c|c|c|}
\hline \multirow{2}{*}{ Date } & \multirow{2}{*}{ Irrigation Status } & \multirow{2}{*}{ Incidence } & \multirow{2}{*}{ Orbit pass } & \multicolumn{3}{|c|}{$\sigma^{0} \mathrm{HH}(\mathrm{dB})$} & \multirow{2}{*}{$\begin{array}{c}\text { BWC }\left(\mathrm{tha}^{-1}\right) \\
\text { Mean }\end{array}$} & \multirow{2}{*}{$\Delta \sigma$} & \multirow{2}{*}{$\mathrm{T} \sigma$} \\
\hline & & & & $\min$ & Mean & $\max$ & & & \\
\hline 02/02/2008 & & 3 & $\mathrm{D}$ & -10.5 & -9.7 & -8.9 & 4.5 & 1.2 & 0.0 \\
\hline 05/02/2008 & & 1 & A & -8.9 & -8.1 & -6.4 & 5.4 & 1.7 & 0.0 \\
\hline $08 / 02 / 2008$ & under irrigation & 2 & A & -10.8 & -9.4 & -5.0 & 6.5 & 4.7 & \\
\hline $11 / 02 / 2008$ & under irrigation & 4 & A & -12.4 & -10.3 & -7.1 & 7.9 & 3.3 & \\
\hline $14 / 02 / 2008$ & under irrigation & 6 & A & -12.1 & -9.9 & -8.0 & 9.3 & 2.7 & \\
\hline $15 / 02 / 2008$ & under irrigation & 6 & $\mathrm{D}$ & -12.9 & -10.5 & -8.7 & 9.8 & 3.3 & \\
\hline $21 / 02 / 2008$ & under irrigation & 2 & $\mathrm{D}$ & -10.8 & -6.7 & -4.8 & 12.9 & 5.9 & \\
\hline $24 / 02 / 2008$ & & 2 & A & -10.6 & -6.4 & -3.6 & 14.7 & 0.0 & 0.4 \\
\hline $27 / 02 / 2008$ & & 3 & A & -11.5 & -9.2 & -6.8 & 16.5 & 0.2 & 0.3 \\
\hline 05/03/2008 & & 4 & $\mathrm{D}$ & -12.4 & -11.6 & -9.9 & 20.7 & 0.4 & 0.1 \\
\hline $08 / 03 / 2008$ & under irrigation & 3 & $\mathrm{D}$ & -11.8 & -10.6 & -8.3 & 22.5 & 2.8 & \\
\hline $11 / 03 / 2008$ & under irrigation & 1 & A & -10.2 & -8.4 & -5.4 & 24.5 & 4.1 & \\
\hline $11 / 03 / 2008$ & under irrigation & 1 & $\mathrm{D}$ & -9.9 & -8.1 & -5.6 & 24.5 & 3.6 & \\
\hline $17 / 03 / 2008$ & under irrigation & 4 & A & -12.7 & -11.2 & -9.5 & 28.1 & 3.1 & \\
\hline $20 / 03 / 2008$ & & 6 & A & -12.5 & -11.4 & -9.7 & 30.2 & 0.3 & 0.1 \\
\hline $27 / 03 / 2008$ & & 2 & $\mathrm{D}$ & -11.6 & -9.6 & -7.5 & 34.1 & 0.8 & 0.2 \\
\hline 09/04/2008 & under irrigation & 4 & $\mathrm{D}$ & -13.0 & -11.3 & -9.1 & 16.6 & 3.5 & \\
\hline $12 / 04 / 2008$ & under irrigation & 3 & $\mathrm{D}$ & -11.1 & -9.1 & -7.1 & 14.2 & 0.8 & \\
\hline $15 / 04 / 2008$ & & 1 & A & -10.6 & -7.7 & -4.2 & 12.3 & 0.4 & 0.4 \\
\hline $15 / 04 / 2008$ & & 1 & $\mathrm{D}$ & -9.4 & -7.2 & -4.9 & 12.3 & 1.4 & 0.3 \\
\hline $21 / 04 / 2008$ & & 4 & A & -12.6 & -11.6 & -10.4 & 9.1 & 1.0 & 0.0 \\
\hline
\end{tabular}

period to preclude $\sigma^{0} \mathrm{HH}$ spatial discontinuity. T $\sigma$ is supposed to be maximal just after irrigation, then to decrease with time as the topsoil dries.

Amplitudes and trends values are displayed in Table 1 together with $\sigma^{0} \mathrm{HH}$ average and extreme values. Firstly, it appears that the mean level of $\sigma^{0} \mathrm{HH}$ logically decreases with incidence angle: its minimun value across the segments is on average $-9.8,-10.9,-11.3,-12.6,-12.5 \mathrm{~dB}$ for IS1, IS2, IS3, IS4 and IS6, respectively. More interestingly, $\Delta \sigma$ is much larger during irrigation times $(3.4 \mathrm{~dB}$ on average, grey lines in Table 1) than out of irrigation times $(0.7 \mathrm{~dB}$ on average, white lines in Table 1). The magnitude of the difference between wet and dry status highlighted by the $\Delta \sigma$ index is consistent with the variation of backscattering coefficients reported by Brown et al. (2003) and Mattia et al. (2003) for wheat fields observed before and after rain events. This is consistent with previous findings of Ulaby et al. (1979) that showed that the difference in the radar signal between wet and dry soil conditions is several $\mathrm{dB}$ at $4.25 \mathrm{Ghz}$, and that this difference was observed for viewing angles between $0^{\circ}$ and $60^{\circ}$ for a $1 \mathrm{~m}$ height wheat crop. Furthermore, the irrigation limits are detected without ambiguity, whatever the range of biomass water content and the incidence angle: $\Delta \sigma$ is on average $4 \mathrm{~dB}$ for the six images acquired during the first irrigation time, with a mean BWC of $9.3 \mathrm{tha}^{-1}$; it is $3.4 \mathrm{~dB}$ for the four images acquired during the second irrigation time, with a BWC of $24.9 \mathrm{tha}^{-1}$. These values are much higher than the acquisition error estimated around $0.85 \mathrm{~dB}$ (see Sect. 2.3.2). Finally, the effect of topsoil drying is clearly visible looking at the trend of $\sigma^{0} \mathrm{HH}$ along the various segments out of irrigation times ( $\mathrm{T} \sigma$ in Table 1 . T $\sigma$ is almost null just before irrigations because the topsoil is homogenously dry $(02 / 02 / 08$, $05 / 02 / 2008$ and $21 / 04 / 2008$ in Table 1 ). In contrast, T $\sigma$ is maximal at the middle of irrigation times when the topsoil moisture is the most different between the non-irrigated dry segments and the irrigated wet one. To tends to decrease from date to date after irrigation as the topsoil becomes homogeneously dry $(24 / 02 / 2008$ to $05 / 03 / 2008$ after the first irrigation time in Table 1).

In order to compare the sensitivity of backscattering coefficients between $\mathrm{HH}$ and VV polarizations, we also computed the amplitude variation for $\mathrm{VV}$ observations $\left(\Delta \sigma_{\mathrm{VV}}\right)$. Not shown here, $\Delta \sigma_{\mathrm{VV}}$ was found on average $2.9 \mathrm{~dB}, 2.0 \mathrm{~dB}$ and $1.2 \mathrm{~dB}$ during the first, the second and the third irrigation times, respectively. $\Delta \sigma_{\mathrm{VV}}$ is thus lower than the amplitude variation for $\mathrm{HH}$ observations (around $4.0 \mathrm{~dB}, 3.4 \mathrm{~dB}$, and $2.1 \mathrm{~dB}$, see Table 1 ), by on average $1.1 \mathrm{~dB}$ for the images acquired during irrigation times. As stated in Brown et al. (2003) and Mattia et al. (2003), backscattering in VV polarization is much more attenuated by vegetation than 
backscattering in $\mathrm{HH}$ polarization. As a consequence, differences between wet and dry conditions are higher for $\mathrm{HH}$ polarization compared to $\mathrm{VV}$ polarization. We thus have considered $\mathrm{HH}$ polarization for the retrieval of the topsoil moisture in all what follows.

\section{Retrieval of surface soil moisture}

The empirical method for topsoil moisture retrieval is based on the following assumptions: (i) over a large agricultural area, extreme (dry and wet) soil moisture conditions are always observed, (ii) agricultural practices are standardized, thus there is a nearly constant surface roughness for all the crops at a particular stage. In these conditions, it is believed that surface roughness is constant on wheat fields with a given biomass water constant and, consequently, that the dynamic of backscattering coefficient can be related to topsoil moisture.

To meet these requirements, the method is applied on numerous wheat crops (192 fields) with row only oriented North-South. The method is set up through the analysis of the overall range of $\sigma^{0} \mathrm{HH} \times \mathrm{BWC}$ values obtained on these fields all over the growing season for each ASAR illumination/viewing condition. This also allows to understand and to account for the variation of backscattering coefficients between the ASAR viewing conditions. On the example displayed in Fig. 7, we can observe a regular decrease of both the $\sigma^{0} \mathrm{HH}$ level and the $\sigma^{0} \mathrm{HH}$ dynamic range as a function of $\mathrm{BWC}$, which is due to the attenuation of backscattering by the vegetation. The $\sigma^{0} \mathrm{HH} \times \mathrm{BWC}$ scatterplot thus displays a trapezoid shape with upper and lower edges well identified by simple lines. Given the above-mentioned assumptions, minimal and maximal values of backscattering coefficient along these lines correspond to dry (bottom line) and wet (top line) conditions, thus to extrema of topsoil moistures. After the derivation of these extrema from in-situ measurements, the topsoil moisture can be computed for each field and each acquisition date using a linear relationship (Ulaby et al., 1979; Dobson and Ulaby, 1986; Champion and Faivre, 1997; Le Hegarat et al., 2002; Holah et al., 2005) as:

$\mathrm{H}=\mathrm{H}_{\min }+\left(\mathrm{H}_{\max }-\mathrm{H}_{\min }\right) \times\left(\sigma^{\circ} \mathrm{HH}-\sigma^{\circ} \mathrm{HH}_{\min }\right) /\left(\sigma^{\circ} \mathrm{HH}_{\max }-\sigma^{\circ} \mathrm{HH}_{\min }\right)$

Where :

$\mathrm{H}_{\min }$ and $\mathrm{H}_{\max }$ are the minimal $(6.6 \%)$ and maximal $(55.5 \%)$ topsoil moisture values observed at field;

$\sigma_{\text {HHmin }}^{0}$ and $\sigma^{0}{ }_{\text {HHmax }}$ are the minimal and maximal backscattering coefficient values computed for a given BWC using the dry and wet lines. These lines were derived using an automatic algorithm for selecting $\sigma^{0}{ }_{\mathrm{HH}} / \mathrm{BWC}$ couples using the following rule. The selection might not overrepresent areas where the density of points is high and vice versa (see in Fig. 7, the density of points with low water content is much higher than that the high water content). To meet this requirement, the selection of points is performed

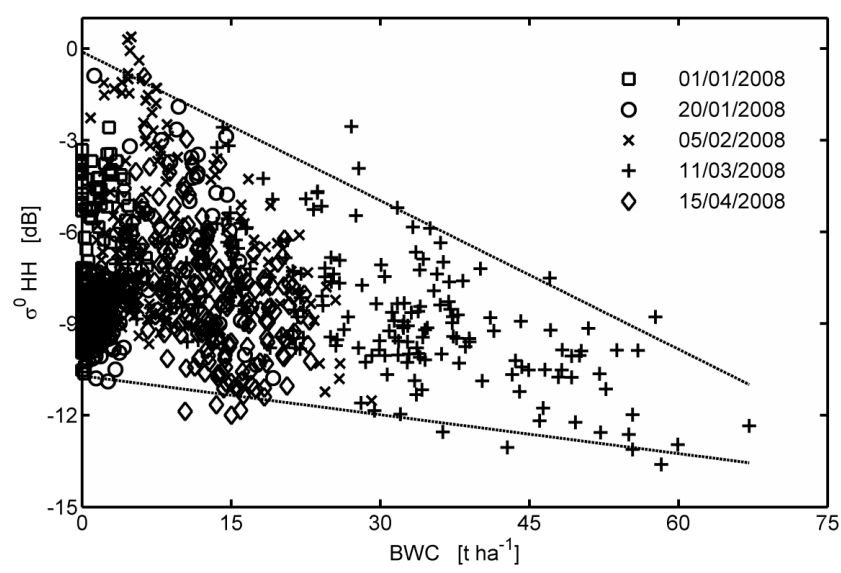

Fig. 7. Backscattering coefficients $\left(\sigma^{0} \mathrm{HH}\right)$ versus biomass water content (BWC) for ASAR images acquired in ascending orbit and incidence angle IS1. Each symbol corresponds to one satellite overpass. The wet (top) and dry (bottom) lines are displayed.

successively on regular BWC intervals of $10 \mathrm{tha}^{-1}$. On each of these intervals, at least 3 couples are selected. Then the lines are fitted on all the selected couples.

The Table 2 displays the number of images available in each geometric configuration, together with the values of two indicators that allows to study the shape of $\sigma^{0} \mathrm{HH} \times \mathrm{BWC}$ trapezoids: D0 is the $\sigma^{0} \mathrm{HH}$ distance between wet and dry conditions for bare soils, i.e. the distance between the upper and the lower edge of the trapezoid at BWC equal to $0 \mathrm{tha}^{-1}$; D45 is the range of $\sigma^{0} \mathrm{HH}$ variation between wet and dry conditions for fully developed canopies, i.e. the distance between the upper and the lower edge of the trapezoid at BWC equal to $45 \mathrm{tha}^{-1}$. The analysis of these indicators shows that:

- There is a high sensitivity of backscattering coefficients to moisture conditions. D0 is always larger than $7 \mathrm{~dB}$, D45 is almost all the time larger than 2.4 except for two cases (IS3-Ascending and IS6-Descending in Table 2). For these two cases, there is no image acquired at the middle of the growing season when the biomass water content is the highest (end of February for IS3A, end of April for IS6, see Fig. 1). This limits the data used in the delineation of dry and wet lines and, consequently, the accuracy in their definition.

- There is a consistency in the indicators between the images acquired in ascending and descending modes with the same incidence angle. D0 regularly decreases from low (IS1) to high (IS6) incidence angle, by about $4.5 \mathrm{~dB}$. D45 also decreases with the incidence angle, though in a less extent, from about $4 \mathrm{~dB}$ at IS1 to $2 \mathrm{~dB}$ at IS6. 
Table 2. Number of images available for each ASAR viewing configuration, and $\sigma^{0} \mathrm{HH}$ distance between wet and dry conditions for bare soils (D0) and for fully developed canopies (D45).

\begin{tabular}{lcccc}
\hline Incidence & Orbit pass & Images used & D0 & D45 \\
\hline 1 & A & 5 & 11.2 & 4.7 \\
1 & D & 3 & 11.7 & 4.6 \\
2 & A & 4 & 10.1 & 2.9 \\
2 & D & 3 & 9.3 & 4.2 \\
3 & A & 2 & 9.0 & 1.6 \\
3 & D & 4 & 9.6 & 3.9 \\
4 & A & 4 & 7.7 & 3.1 \\
4 & D & 5 & 7.2 & 2.8 \\
6 & A & 4 & 7.0 & 2.4 \\
6 & D & 3 & 7.0 & 0.6 \\
\hline
\end{tabular}

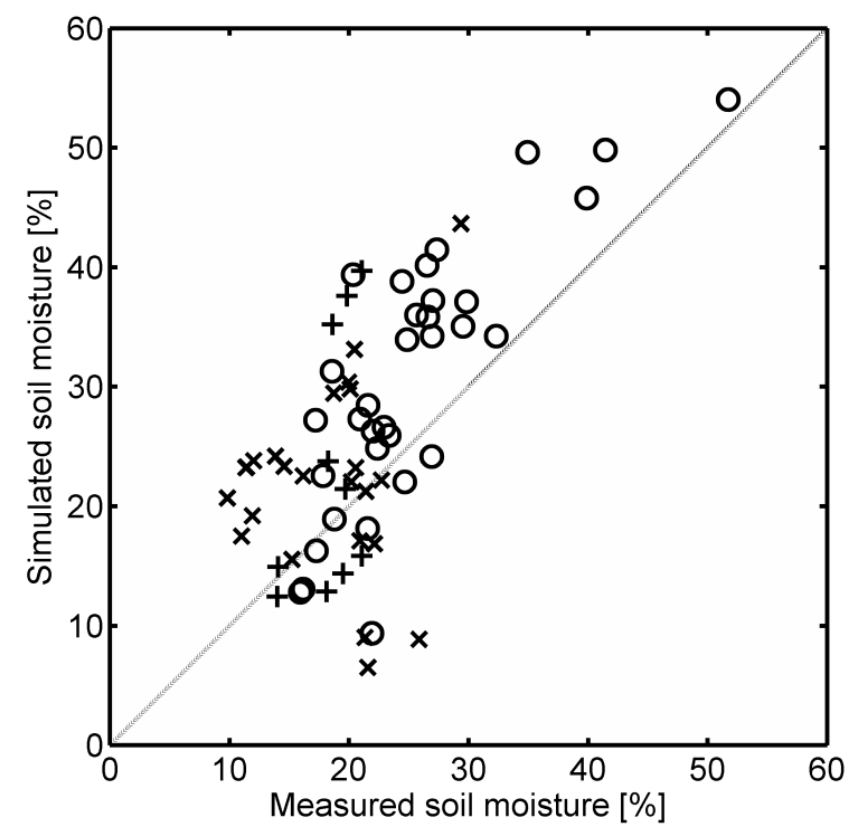

Fig. 8. Estimated versus measured topsoil moisture. The different symbols correspond to three successive wheat vegetative periods: (i) the beginning ("+") with biomass water content (BWC) between 0 to $5 \mathrm{tha}^{-1}$, (ii) the middle ("o") before senescence starts with BWC between 5 and $65 \mathrm{tha}^{-1}$, and the end (" $\times$ ") associated to leaf senescence.

The retrieval of top soil moisture (Eq. 3) is independently applied for each image using the dry and wet lines associated with a given acquisition geometry. The whole processing results in estimates of topsoil moisture for 192 fields with row oriented North-South all over the study area at each satellite overpass.

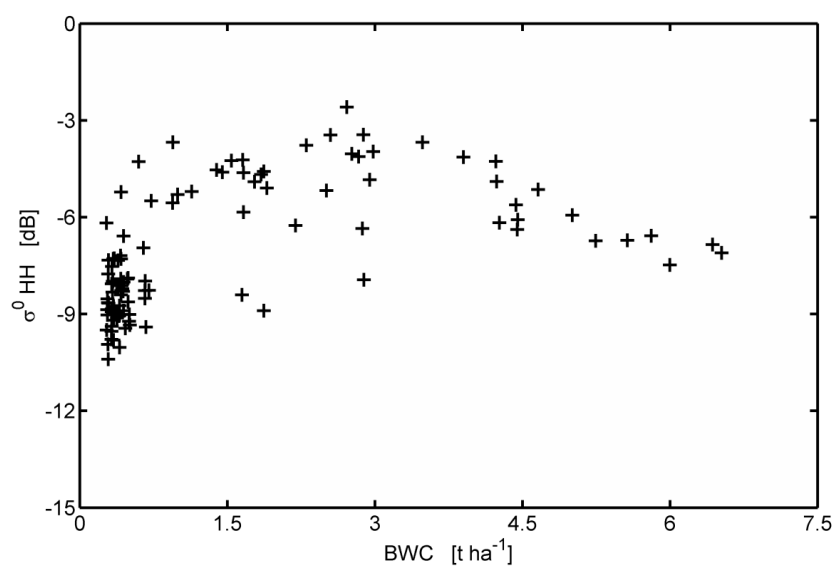

Fig. 9. $\sigma^{0} \mathrm{HH}$ to biomass water content scatterplot at the agricultural season beginning for fields with North-South row orientations (ASAR image acquired the 01/01/2008, in ascending orbit, and incidence angle 1$)$.

The retrieved values are compared to the topsoil moisture measured using TDR sensors. It should be kept in mind that these measurements are very local, whereas the values derived from $\sigma^{0}{ }_{\mathrm{HH}}$ correspond to 5 ha area. The result of this comparison is displayed in Fig. 8. The agreement between estimated and measured topsoil moisture is globally rather poor $\left(R^{2}=0.48\right.$, RMSE $=9.8 \%, 47 \%$ in relative value $)$, but a deep analysis shows that it depends on the wheat growing phase:

- at the beginning of the agricultural season (" +" symbols in Fig. 8, BWC between 0 to $5 \mathrm{tha}^{-1}$ ), there is no relationship at all between estimates and measurements. In order to get a better understanding of this scattering, we analysed the variation of $\sigma^{0} \mathrm{HH}$ as a function of the biomass water content for the first acquisition date. At this time of year, BWC ranges between 0 and $7 \mathrm{tha}^{-1}$, whereas the topsoil is rather dry since the first irrigation is not operated. Topsoil moisture was around $19 \%$ for the two fields equipped with TDR probes. In this case, $\sigma^{0} \mathrm{HH}$ appears mainly sensitive to the biomass water content, displaying a peak when BWC reaches 3 tha $^{-1}$ (Fig. 9).

- at the end of the agricultural season (" $x$ " symbols in Fig. 8), the method also provides with poor results. A probable explanation is that estimates are attempted for fields in very different conditions: mature and senescent canopies or dry plant litter after harvest.

- for the intermediate case, i.e. BWC between 5 and $65 \mathrm{tha}^{-1}$ before senescence starts, ("o" symbols in Fig. 8), the estimated topsoil moisture appears well correlated with observation: $R^{2}$ is around 0.64 and the RMSE is $8.8 \%\left(0.088 \mathrm{~m}^{3} \mathrm{~m}^{-3}, 34 \%\right.$ in relative value $)$. 


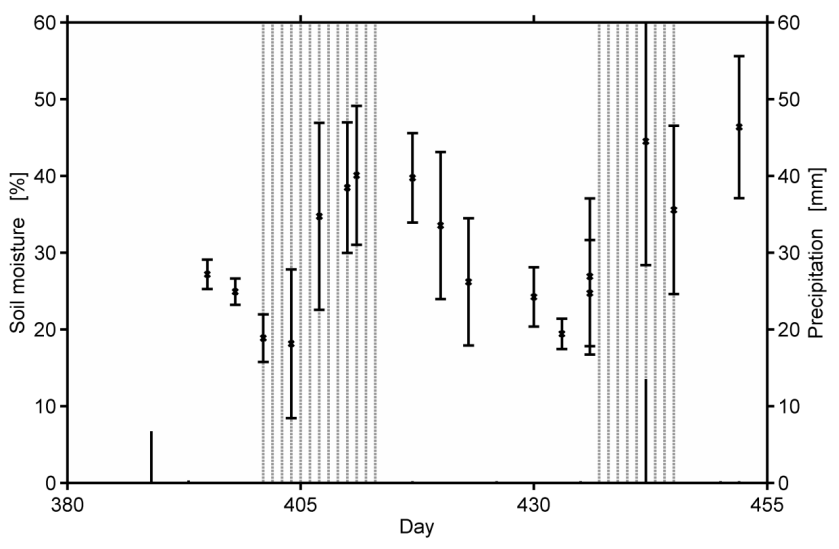

Fig. 10. Time course of topsoil moisture (average and standard deviation) retrieved on field 5 together with the irrigation periods (vertical dotted gray lines) and precipitation (black line at the bottom of the y-axis). The days are numbered from 1 January 2007.

A deeper examination of these data did not allow to make a distinction neither between the different acquisition geometry nor between the different stages of vegetation growing. This means that the inversion procedure works even for high incidence angles and when the vegetation is fully developed.

In order to evaluate the spatial and temporal variations of topsoil moisture, the inversion procedure was applied on the twelve fields where irrigation practices were recorded (see Fig. 1). According to the previous finding, the inversion algorithm was set up only when the biomass water content exceeds $5 \mathrm{tha}^{-1}$ and in absence of plant senescence, i.e. when the air temperature accumulated from emergence is below the threshold defining the senescence temperature in the SAFY model.

The Table 3 shows the topsoil moisture derived from ASAR averaged on a 5-day period before and after the first and the second irrigation times. In most of cases, the values of topsoil moisture appear consistent with the irrigation schedules: topsoil moisture ranges from about 9 to $31 \%$ before the irrigation times and from $20 \%$ to $50 \%$ after irrigation times; their averaged values are much lower before irrigation times $(24 \%$ and $21 \%$ for the first and the second irrigation, respectively) than after ( $40 \%$ and $33 \%$ for the first and the second irrigation, respectively). This general trend is preserved for 10 of the 12 fields analysed, except on : (i) field 1 , where the topsoil moisture is higher before than after the first irrigation time and the value before the second irrigation appear unrealistically low; (ii) field 3, where the topsoil appear dry both before and after the second irrigation time. Additional data would be necessary to explain why the method fails in these two cases, still the main possible causes are miss-collection of irrigation data (periods and/or amounts) and local variations of the soil properties (texture, roughness).
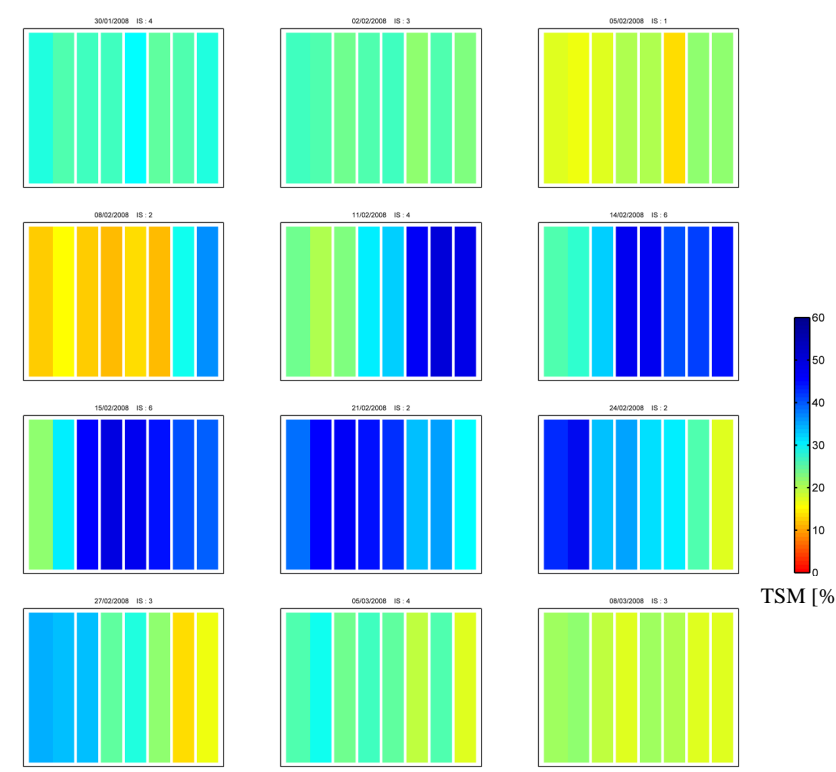

TSM $[\%]$

Fig. 11. Topsoil moisture (TSM) mapped over the different geographical units (about 5 ha) of the field 5 (see Table 3 and Fig. 1). The 12 first dates, corresponding to those shown on Fig. 10, are presented together with the incidence angle of the based Envisat acquisition.

Finally, a detailed analysis of the temporal and spatial variations of topsoil moisture is presented for field 5 as a representative case (Figs. 10 and 11). On this field, the time course of the mean topsoil moisture appears coherent with the irrigation schedules all over the season: the topsoil moisture sharply rises during irrigation times then continuously decreases after irrigation times (Fig. 10). Figure 11 displays the spatial variations of the topsoil moisture derived over the 8 segments within the field 5 from the 12 ASAR images successively acquired around the first irrigation time. Before irrigation, the topsoil moisture appears homogeneous with a slight decrease from the first image (30/01/2008) to the third $(05 / 02 / 2008)$. The watercourse can be easily identified from the images acquired at the time of irrigation (08/02/2008 to 21/02/2008): the topsoil moisture suddenly increases on several segments (blue to red colors in Fig. 11), firstly on the eastern part of the field (08/02/2008 and 11/02/2008), then on the middle $(14 / 02 / 2008)$ and on the western parts $(15 / 02 / 2008$ and $21 / 02 / 2008)$. After irrigation (21/02/2008 to $08 / 03 / 2008$ ), the topsoil moisture continuously decreases and the impact of irrigation on its spatial distribution is smoothed with time. All this is also visible when looking at the standard deviation of the mean topsoil moisture calculated over the 8 segments included in field 5 (Fig. 10). The standard deviation is minimal before and a long time after the first irrigation time when the soil is homogeneously dry; it is maximal at the middle of irrigation times when segments may not been irrigated yet, under irrigation or already irrigated. 
Table 3. Topsoil moisture derived from ASAR image before and after the first and the second irrigations on the twelve fields where irrigation schedules were collected during the experiment.

\begin{tabular}{|c|c|c|c|c|c|c|c|c|c|}
\hline \multirow{2}{*}{ Fields } & \multirow{2}{*}{ Area (ha) } & \multicolumn{2}{|c|}{ Before Irrigation 1} & \multicolumn{2}{|c|}{ After Irrigation 1} & \multicolumn{2}{|c|}{ Before Irrigation 2} & \multicolumn{2}{|c|}{ After Irrigation 2} \\
\hline & & $\mathrm{Nb}$ Image & Mean & $\mathrm{Nb}$ Image & Mean & $\mathrm{Nb}$ Image & Mean & $\mathrm{Nb}$ Image & Mean \\
\hline 1 & 32.8 & 2 & 29.1 & 3 & 27.7 & 2 & 8.6 & 2 & 23.7 \\
\hline 2 & 45.1 & 0 & $\mathrm{x}$ & 2 & 46.2 & 2 & 29.1 & 0 & $\mathrm{X}$ \\
\hline 3 & 22.8 & 0 & $\mathrm{x}$ & 1 & 33.2 & 3 & 16.5 & 2 & 19.8 \\
\hline 4 & 47.8 & 2 & 31.5 & 2 & 44.7 & 2 & 19.2 & 2 & 39.1 \\
\hline 5 & 48.1 & 2 & 21.9 & 1 & 39.7 & 3 & 23.7 & 1 & 35.5 \\
\hline 6 & 47.1 & 0 & $\mathrm{x}$ & 3 & 44.5 & 2 & 28.6 & 2 & 35.2 \\
\hline 7 & 19.7 & 1 & 29.1 & 2 & 42.3 & 1 & 18.9 & 1 & 35.9 \\
\hline 8 & 19.1 & 2 & 20.9 & 1 & 46.6 & 3 & 12.6 & 2 & 21.0 \\
\hline 9 & 19.0 & 0 & $\mathrm{x}$ & 0 & $\mathrm{x}$ & 1 & 21.4 & 2 & 45.7 \\
\hline 10 & 19.2 & 2 & 16.6 & 1 & 49.3 & 2 & 12.9 & 1 & 40.0 \\
\hline 11 & 76.3 & 1 & 20.0 & 2 & 31.6 & 2 & 28.0 & 1 & 36.5 \\
\hline 12 & 94.0 & 2 & 24.1 & 2 & 38.6 & 1 & 27.9 & 0 & $\mathrm{x}$ \\
\hline
\end{tabular}

\section{Conclusion}

The potentialities of ASAR data for the monitoring of soil moisture conditions in agricultural lands were investigated for wheat crops monitored through the SAFY vegetation functioning model and time series of Formosat-2 images. The normalized difference vegetation index derived from Formosat-2 data was linked to the green leaf area index (GLA) with an accuracy of about $25 \%$. GLA is a key variable for the parametrization of photosynthesis, which was incorporated into the SAFY model to provide spatial estimates of biomass water content (BWC) over up to 200 wheat fields. The value of Formosat-2 data acquired with both a high spatial resolution and a frequent revisit for the monitoring of crop growth should be firstly underlined. It allows increasing the number of data available to get a better understanding of radar signal over irrigated wheat fields.

Despite the homogeneity of agricultural practices and of wheat canopies in the Yaqui area, the joint analysis of radar backscattering $\left(\sigma^{0} \mathrm{HH}\right)$ and BWC shows the complexity of the radar response for agricultural lands, due to a high variability of both surface roughness and topsoil moisture. The sensitivity of the backscattering coefficient to topsoil moisture is highlighted for a large field for which spatial trends and discontinuities of $\sigma^{0} \mathrm{HH}$ were observed in consistency with soil watering during irrigation times and soil drying out of irrigation times. This sensitivity was observed whatever the acquisition angle and whatever the recovering of soil by vegetation, even when BWC was very high. This approach appears suitable to detect on-going irrigated areas all over the wheat growing season.

This previous findings allow to set up an empirical method for the retrieval of topsoil moisture from the combination of ASAR images and spatial estimates of BWC. The method is original since it is based on the spatial variation of $\sigma^{0} \mathrm{HH}$ over a large area rather than on its temporal variation over a particular area. The method allows the retrieval of topsoil moisture from its minimal to its maximal value $(6 \%-56 \%)$ with an error about $9 \%\left(0.09 \mathrm{~m}^{3} \mathrm{~m}^{-3}, 35 \%\right.$ in relative value $)$ for a long period between wheat tillering and senescence phases. These performances appear significant since estimates are performed at the key time of crop growth and under a large range of biomass water content (from 5 to $65 \mathrm{tha}^{-1}$ ) with all ASAR images available (whatever the incidence angles from 15 to $40^{\circ}$ ).

The method provides estimates of topsoil moisture at a field resolution ( $\sim 5 \mathrm{ha})$ without an exact knowledge on surface roughness. An additional advantage is that it not required to normalise satellite observations at a same incidence angle, which is not trivial on surfaces that experiences quick variations such as wheat fields. All these points make the method very attractive for operational application over large areas. However, the method requires the availability of numerous images both in the solar and the micro-wave domain of the electromagnetic spectrum. Furthermore, it was assumed that the surface roughness is stable at a given growing phase (same biomass water content). This assumption is verified in the case of the Yaqui area where large fields are flattened and cropped with modern and mechanized agricultural practices. Application to other areas where these conditions are not met would require adaptation, especially if the region is not rather homogeneous in terms of agricultural practices.

Acknowledgements. The Yaqui 2007-2008 experiment was organized jointly by the IRD-CESBIO, ITSON, UNISON and COLPOS institutions with fundings of the European Union (7th PCRD, PLEIADeS program, http://www.pleiades.es/), the French INSUPNTS ("Programme National de Télédétection Spatiale") and CNES-TOSCA ("Terre Océan Surface Continentale Atmosphère") 
programs and the Mexican CONACYT program. We are indebted to ESA for the programming and the delivery of ASAR images as well as to NSPO, SPOT-Image, and CNES for the programming, the delivery and the processing of Formosat- 2 images.

Edited by: D. F. Prieto

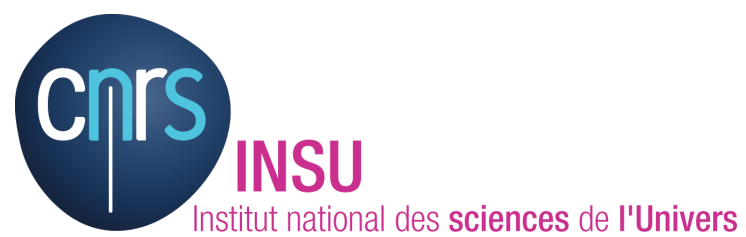

The publication of this article is financed by CNRS-INSU.

\section{References}

Asrar, G., Fuchs, M., Manemasu, E. T., and Hatfield, J. L.: Estimating absorbed photosynthetic radiation and leaf area index from spectral reflectance in wheat, Agron. J., 76, 300-306, 1984.

Baret, F. and Guyot, G.: Potentials and limits of vegetation indices for LAI and APAR assessment, Remote Sens. Environ., 35, 161173, 1991.

Bastiaanssen, W. G. M., Molden, D. J., and Makin, I. W.: Remote sensing for irrigated agriculture: examples from research and possible applications, Agr. Water Manage., 46, 137-155, 2000.

Beaudoin, A., Le Toan, T., and Gwyn, Q. H. J.: SAR observations and modeling of the C-band backscatter variability due to multiscale geometry and soil moisture, IEEE T. Geosci. Remote, 28(5), 886-895, 1990.

Boote, K. J., Jones, J. W., and Pickering, N. B.: Potential uses and limitations of crop models, Agron. J., 88, 704-716, 1996.

Bracaglia, M., Ferrazzoli, P., and Guerriero, L.: A fully polarimetric multiple scattering model for crops, Remote Sens. Environ., 54, 170-179, 1995.

Brown, S. C. M., Quegan, S., Morrison, K., Bennett, J. C., and Cookmartin, G.: High-Resolution Measurements of Scattering in Wheat Canopies-Implications for Crop Parameter Retrieval, IEEE T. Geosci. Remote, 41(7), 1602-1610, 2003.

Bsaibes, A., Courault, D., Baret, F., Weiss, M., Olioso, A., Jacob, F., Hagolle, O., Marloie, O., Bertrand, N., Desfond, V., and Kzemipour, F.: Albedo and LAI estimates from FORMOSAT-2 data for crop monitoring, Remote Sens. Environ., 113, 716-729, 2009.

Carlson, T. N. and Ripley, D. A.: On the relation between NDVI, vegetation cover and leaf area index, Remote Sens. Environ., 62, 241-252, 1997.

Champion, I. and Faivre, R.: Sensitivity of the radar signal to soil moisture: variation with incidence angle, frequency and polarization, IEEE T. Geosci. Remote, 35, 781-783, 1997.

Chern, J.-S., Ling, J., and Weng, S.-L.: Taiwan's second remote sensing satellite, Acta Astronaut., 63, 1305-1311, 2008.

Claverie, M., Demarez, V., Duchemin, B., Maire, F., Hagolle, O., Keravec, P., Marciel, B., Ceschia, E., Dejoux, J.-F., and Dedieu, G.: Spatialisation of crop Leaf Area Index and Biomass by combining a simple crop model and high spatial and temporal resolu- tions remote sensing data, Int. Geosci. Remote Se., Cape Town, South Africa, 2009.

Dente, L., Satalino, G., Mattia, F., and Rinaldi, M.: Assimilation of leaf area index derived from ASAR and MERIS data into CERES-Wheat model to map wheat yield, Remote Sens. Environ., 112, 1395-1407, 2008.

Dobson, M. C. and Ulaby, F. W.: Active microwave soil moisture research. IEEE T. Geosci. Remote, 24, 23-6, 1986.

Duchemin, B., Hadria, R., Er-Raki, S., Boulet, G., Maisongrande, P., Chehbouni, A., Escadafal, R., Ezzahar, J., Hoedjes, J., Kharrou, M. H., Khabba, S., Mougenot, B., Olioso, A., Rodriguez, J.-C., and Simonneaux, V.: Monitoring wheat phenology and irrigation in Center of Morocco: on the use of relationship between evapotranspiration, crops coefficients, leaf area index and remotely-sensed vegetation indices, Agr. Water Manage., 79, 127, 2006.

Duchemin, B., Hagolle, O., Mougenot, B., Benhadj, I., Hadria, R., Simonneaux, V., Ezzahar, J., Hoedjes, J., Khabba, S., Kharrou, M. H., Boulet, G., Dedieu, G., Er-Raki, S., Escadafal, R., Olioso, A., and Chehbouni, A. G.: Agrometerological study of semi-arid areas: an experiment for analysing the potential of FORMOSAT2 time series of images in the Tensift-Marrakech plain, Int. J. Remote Sens., 29, 5291-5300, 2008a.

Duchemin, B., Maisongrande, P., Boulet, G., and Benhadj, I.: A simple algorithm for yield estimates: calibration and evaluation for semi-arid irrigated winter wheat monitored with groundbased remotely-sensed data, Environ. Modell. Softw., 23, 876892, 2008b.

Duchemin, B., Fieuzal, R., Augustin Rivera, M., Boulet, G., ErRaki, S., Ezzahar, J., Mougenot, B., Perez-Ruiz, E. R., Rodriguez, J. C., Hagolle, O., Garatuza-Payan, J., Watts, C., Escadafal, R., and Chehbouni, A.: Impact of sowing date on yield and water-use-efficiency of wheat analyzed through spatial modeling and FORMOSAT-2 images, submitted to Remote Sens. Environ., 2010.

ESA: GMES Sentinel-2 mission requirement document, No. EOPSM/1163/MR-dr v2.0, http://esamultimedia.esa.int/docs/GMES/ Sentinel-2_MRD.pdf, (2007).

Faivre, R., Leenhardt, D., Voltz, M., Benoit, M., Papy, F., Dedieu, G., and Wallach, D.: Spatialising crop models, Agronomie, 24, 205-217, 2004.

Garrigues, S., Allard, D., Baret, F., and Weiss, M.: Quantifying spatial heterogeneity at the landscape scale using variogram models, Remote Sens. Environ., 103, 81-96, 2006.

Hadria, R., Duchemin, B., Jarlan, L., Dedieu, G., Baup, F., Khabba, S., Olioso, A., and Le Toan, T.: Potentiality of optical and radar satellite data at high spatio-temporal resolutions for the monitoring of irrigated wheat crops in Morocco, Int. J. Appl. Earth Obs., 12, S32-S37, 2010.

Hagolle, O., Dedieu, G., Mougenot, B., Debaecker, V., Duchemin, B., and Meygret, A.: Correction of aerosol effects on multitemporal images acquired with constant viewing angles: application to Formosat-2 images, Remote Sens. Environ., 112, 16891701, 2008.

Holah, H., Baghdadi, N., Zribi, M., Bruand, A., and King C.: Potential of ASAR/ENVISAT for the characterization of soil surface parameters over bare agricultural fields, Remote Sens. Environ., 96(1), 78-86, 2005.

Jarlan, L., Mougin, E., Frison, P. L., Mazzega, P., and Hiernaux, 
P.: Analysis of ERS wind scatterometer time series over Sahel (Mali), Remote Sens. Environ., 81, 404-415, 2002.

Le Hégarat-Mascle, S., Zribi, M., Alem, F., and Weisse, A.: Soil moisture estimation from ERS/SAR data: Toward an operational methodology, IEEE T. Geosci. Remote, 40(12), 26472658, 2002.

Lobell, D. B., Ortiz-Monasterio, J. I, Asner, G. P., Matson, P. A, Naylor, R. L., and Falcon, W. P.: Analysis of wheat yield and climatic trends in Mexico, Field Crop. Res., 94, 250-256, 2005.

Maas, S. J.: Parameterized model of gramineous crop growth, 1. Leaf-area and dry mass simulation, Agron. J., 85, 348-353, 1993.

Mattia, F., Le Toan, T., Picard, G., Posa, F. I., D'Alessio, A., Notarnicola, C., Gatti, A. M., Rinaldi, M., Satalino, G., and Pasquariello, G.: Multitemporal C-Band Radar Measurements on Wheat Fields, IEEE T. Geosci. Remote, 41(7), 1551-1560, 2003.

Monteith, J. L. and Moss, C. J.: Climate and the Efficiency of Crop Production in Britain, Philos. T. Roy. Soc. B, 281, 277294, 1977.

Moran, M. S., Hymer, D. C., Qi, J., and Kerr, Y.: Comparison of ERS-2 SAR and Landsat TM imagery for monitoring agricultural crop and soil conditions, Remote Sens. Environ., 79, 243-252, 2002.

Moulin, S., Bondeau, A., and Delécolle, R.: Combining agricultural crop models and satellite observations from field to regional scales, Int. J. Remote Sens., 19, 1021-1036, 1998.

Ortiz-Monasterio, J. I. and Lobell, D. B.: Remote sensing assessment of regional yield losses due to sub-optimal planting dates and fallow period weed management, Field Crop. Res., 101, 8087, 2007.

Picard, G., Le Toan, T., and Mattia, F.: Understanding C-band radar backscatter from wheat canopy using a multiple-scattering coherent model, IEEE T. Geosci. Remote Sens., 41(7), 1583-1591, 2003.
Rahman, H. and Dedieu, G.: SMAC: a simplified method for the atmospheric correction of satellite measurements in the solar spectrum, Int. J. Remote Sens., 15.1, 123-143, 1994.

Rodriguez, J.-C., Duchemin, B., Hadria, R., Watts, C., Garatuza, J., Chehbouni, A., Khabba, S., Boulet, G., Palacios, R., and Lahrouni, A.: Wheat yield estimation using remote sensing and the STICS model in the semiarid valley of Yaqui, Mexico, Agronomie, 24, 295-304, 2004.

Satalino, G., Mattia, F., Davidson, M., Le Toan, T., Pasquarello, G., and Borgeaud, M.: On current limits of Soil Moisture Retrieval from ERS SAR data, IEEE T. Geosci. Remote Sens., 40, 2438 2447, 2003.

Torres, R., Buck, C., Guijarro, J., Suchail, J. L., and Schönenberg, A.: The ENVISAT ASAR Instrument Verification and Characterisation, ESA CEOS SAR Workshop, ESA-SP450, October 1999.

Ulaby, F. T., Bradley, G. A., and Dobson, M. C.: Microwave backscatter dependence on surface roughness in soil moisture and soil texture: Part II-Vegetation-covered soil, IEEE T. Geosci Remote Sens., 17, 33-40, 1979.

Ulaby, F. T., Fung, A. K., and Moore, R. K.: Microwave and remote sensing active and passive (Norwood, MA: Artech House), 1986.

Weiss, M., Baret, F., Smith, G. J., Jonckheere, I., and Coppin, P.: Review of methods for in situ leaf area index (LAI) determination: Part II. Estimation of LAI, errors and sampling, Agr. Forest Meteorol., 121, 37-53, 2004.

Zribi, M., Le Hégarat-Mascle, S., Ottlé, C., Kammoun, B., and Guerin, C.: Surface soil moisture estimation from the synergistic use of the (multi-incidence and multi-resolution) active microwave ERS Wind Scatterometer and SAR data, Remote Sens. Environ., 86, 30-41, 2003. 